\title{
The Characteristics of Social Adaptation of College Freshmen and Educational Strategy
}

\author{
Liqiao $\mathrm{Xu}$ \\ Security Department, Wuhan University of Science and \\ Technology, Wuhan, China \\ 42047165@qq.com
}

\author{
Chuanhua Gu*, Dongjing Zhang, Zhi Jing \\ School of Psychology, Central China Normal University, \\ Wuhan, China \\ guchanhua@mail.ccnu.edu.cn \\ *Corresponding author
}

\begin{abstract}
This study investigated 680 freshmen in Wuhan to analyze the characteristics of their social adaptation with the Scale of College Students' Social Adaptation. The result indicated that, the freshmen from urban areas scored higher significantly on interpersonal adaptation and role adaptation than those from rural areas, but the opposite for the self-care adaptability; the female scored higher on role adaptation and environmentidentification than the male, but the opposite for the self-care adaptability; the only-child students scored higher on interpersonal adaptation and role identification than the child with siblings, but the opposite for the self-care adaptability. Based on the results, the educational strategy for improving freshmen's adaptation was discussed.
\end{abstract}

Keywords- college freshmen; social adaptation; educational strategy

\section{INTRODUCTION}

With the reform of college entrance examination system in China, more and more students have the chance to enter the college to pursue their dreams. However, such problems in life as learning and friendship problems are obsessing them at the same time. As college is an important milestone of one's life, it is significant for freshmen to adapt to college environment well after entrance. It is difficult for the freshmen who enter the college just after the stressful life of high school to accommodate a series of changes in learning and interpersonal relationship in a short time. Usually, they will be confused first, and will not be able to adjust to new life and environment of college immediately without help.

Adaptability is the ability that the individual deals with or accommodates natural and social environment effectively, including the ability to live independently, to manage his own life, meet the cultural requirement [1]. Freshmen's adaptation was studied earlier and more thoroughly in foreign countries. One's social adaptation was associated with his or her family. Janathan and his colleagues verified that parents' attachment affected the adaptation of college freshmen; meanwhile, parents' support was very important for their adaptation [2]. Ericka and Lamia [3] also found that parents' support had affected students' adaptation significantly. What's more, Kenneth et al. considered perfectionism was associated with freshmen's adaptation [4]. Rosalind analyzed the relationship between self-concept and freshmen's social adaptation [5]. There are also some psychological consultants and teaching staff in china studied and analyzed the problem of freshmen's adaptation and its factors [6][7][8][9]. On the intervention of college freshmen's adaptability, Zhang et al. found that class psychological service was helpful for college freshmen to adapt to a new environment [10].

In sum, most of the researchers from home and abroad studied the factors of adaptability qualitatively, but very little quantitative research about freshmen's adaptability has been carried out, and the people do not know clearly about the group difference in the adaptability of freshmen from different areas and with different characteristics. The aim of the current research is to investigate the characteristics of social adaption of college freshmen born after 1990, and analyze their group difference, and then give advice on the education about their social adaptation to help them form the healthy personality and accommodate college life.

\section{RESEARCH METHOD}

\section{A. Participants}

700 freshmen from Wuhan City in Hubei Province of China were selected randomly to fill in the questionnaire a week after entrance into college, and 680 valid copies of the questionnaires were got back, and the recovery rate is $97 \%$. Among the 680 freshmen, 124 were female and 556 were male; 219 were single-child and 461 were child with siblings; 145 were from urban areas and 535 were from rural areas; their majors involved architecture, water supply and drainage, environment design and civil engineering.

\section{B. Questionnaires}

College Freshmen's Adaptability Scale worked out by Xiefeng $\mathrm{Lu}$ in 2008 were used to investigate the social adaptability of college freshmen [11]. The Scale has 7 dimensions: learning adaptability (8 items), interpersonal adaptability (11 items), role adaptability ( 9 items), choice adaptability (9 items), self-care adaptability (6 items), environmental identity adaptability ( 7 items), physical and mental symptoms (10 items), and a validity subscale including 6 items. The internal consistency coefficient (Cronbach's $\alpha$ ) of the scale is 0.90 . So the scale has good reliability. The participants were asked to answer each question or item at a five-point scale: agree, somewhat agree, uncertain, somewhat disagree, disagree. 
Besides, background questionnaire was used to collect the data about participants' gender, family area (i.e. urban area or rural area), single-child or not and other related information.

\section{Data Statistics}

ANOVA and test were used to analyze the data with SPSS16.0.

\section{RESULTS}

\section{A. ANOVA on Each Dimension of College Freshmen's Adaptability}

First, take the family area, gender, single child or not as independent variables and each dimension of college freshmen's social adaptability as dependent variables to carry out ANOVA. The results indicated that family area and gender had significant main effect on college freshmen's adaptability (gender: $\mathrm{F}(1,669)=3.14, \mathrm{p}<0.05$; family area: $\mathrm{F}(1,669)=2.04$, $\mathrm{p}<0.05$ ), and the variable of single-child or not had marginal main effect $(\mathrm{F}(1,669)=1.91, \mathrm{p}<0.10)$, and there was no interaction between the three independent variables.

\section{B. Area Difference of College Freshmen's Social Adaptability}

There were significant area differences in social adaptability, that is, the freshmen from urban areas had different social adaptability from those from rural areas. The result of ANOVA indicated that there were significant differences in interpersonal adaptation, role adaptation, and self-care. Post-test analysis showed that, in the dimension of interpersonal adaptation and role adaptation, students from urban areas scored higher than those from rural area $(\mathrm{t}=13.99$, $\mathrm{p}<0.001 ; \mathrm{t}=5.81, \mathrm{p}<0.001)$, but in the dimension of self-care, students from rural area scored higher than those from urban areas $(\mathrm{t}=7.24, \mathrm{p}<0.001)$.

\section{Gender Difference of College Freshmen's Social Adaptability}

The results of $t$ test indicated that, in the dimensions of role adaptation and environment identity, female scored higher significantly than male $(\mathrm{t}=-2.93, \mathrm{p}<0.01 ; \mathrm{t}=-2.35, \mathrm{p}<0.05)$, but in the dimension of self-care, female scored lower significantly than male $(t=2.51, p<0.05)$.

\section{The Difference of College Freshmen's Social} Adaptability between Single-child and Child with Siblings

The results indicated that on the dimensions of learning adaptability and interpersonal adaptability, single-child scored higher significantly than child with siblings $(\mathrm{t}=3.13, \mathrm{p}<0.01$; $\mathrm{t}=2.68, \mathrm{p}<0.01$ ), but on the dimension of self-care, the result was the opposite $(\mathrm{t}=-2.01, \mathrm{p}<0.05)$.

\section{DISCUSSION}

\section{A. Gender Diference in Freshmen's Social Adaptability}

As the results indicated, on the dimensions of role adaptation and environment identity, the female freshmen scored higher significantly than the male, but male freshmen scored higher than the female on the dimension of self-care. Such results comply with most of the previous studies. Compared to the male, the female can adapt to the new role of freshmen better and faster. They are also good at changing their learning and life style to form new life style according to environmental change. While male freshmen usually ignore the change of details, their self-care ability is comparatively higher. With the fierce social competition, female freshmen from urban areas tend to have more school and occupation pressure than male freshmen. They tend to pay more attention to the environmental change and others' opinions, with more mental pressure and life annoyance than male freshmen.

\section{B. The Difference in Social Adaptability between Single-} child Freshmen and Freshmen as the Child with Siblings

As the result indicated, on the dimensions of learning adaptability and interpersonal adaptability, the single-child scored higher significantly than child with siblings, but on the dimension of self-care, child with siblings scored higher than single-child. Such result shows that it is easier for single-child freshmen to adapt to learning and interpersonal relationship than freshmen as the child with siblings, but single-child freshmen tend to do worse in self-care. For single-child, they have always been the focus of their family, possessing relatively high openness and autonomy. So they are good at making individual plans, preferring exploring learning. It is easier for them to attract peer's attention and to make new friends. But just the family role of "little emperor" makes them do worse in self-care. Meanwhile, parents' excessive care may cause the lack of female freshmen in the ability of living independently and poor self-care ability.

\section{The Difference in Social Adaptability of Freshmen from Different Areas}

On the two dimensions of interpersonal adaptation and role adaptation, urban freshmen scored higher than those from rural areas, but on the dimension of self-care rural freshmen scored higher than urban freshmen. Such results indicate that it is easier for urban freshmen to achieve interpersonal adaptation and role adaptation than those from rural areas, but those students from urban areas will have more trouble in self-care than rural students. Freshmen from urban areas tend to lead a richer and more colorful life, and tend to have complex interpersonal relationship since they were young. So they are good at interacting with others, dealing with interpersonal problems, and changing roles and accommodating to new environment.

But they are not good at doing housework, unable to arrange their life well. While the students from rural areas have more economic pressure, bear more mental pressure after entrance into college. The change from rural area to urban area may increase their difficulty in social adaptation including interpersonal adaptation.

\section{EDUCATIONAL STRATEGy}

Due to the change of living environment, learning style and social role, college freshmen will undergo a process from 
maladjustment to adjustment inevitably. Getting through the adaptive phase smoothly is of great importance for their academic success. The result of the current survey has important implications for the education of freshmen's adaptation.

\section{A. To Carry Out the Investigation into Mental Health for Overall Freshmen and Provide Necessary Guidance}

In the first few weeks after freshmen enter college, related departments of the college should carry out the investigation into mental health and establish psychological file for each freshman immediately so that the responsible person can find and prevent psychological problems of freshmen as early as possible. The teacher responsible for mental health should know about the freshmen's adaptation, and offer immediate help and instruction if necessary. For the freshmen with probable psychological problems, the teacher must offer psychological instructions and solve the problems in the first beginning. The teacher can also carry out group guidance at class for the obvious adaptive problem to help them solve problems of adaptation.

Meanwhile, the responsible administer and teacher should actively build good atmosphere for all freshmen. For example, they can hold a series of lectures about interpersonal interaction to improve the freshmen's consciousness and ability of interpersonal interaction.

\section{B. To Help the Poor Freshmen Learn How to Overcome the Present Difficulty}

For the students from poor rural areas and unable to pay the tuition fee, the teacher should guide them to form the right outlook of life and values, and help them treat and overcome the temporary difficulty correctly. The related personnel in college should let them know about the related national policy such as scholarship for very poor students and the student loan to help the poor students sustain normal learning and life. At the same time, the responsible teacher should take care of them as much as possible, encourage them to live independently and save expenditure, and lead them to find ways of solving the problem including the learning problem.

\section{To Help Students Know About Themselves and Complete the Role Change Actively}

College freshmen will start a new life which is entirely different from that in high school. They have to be away from their parents, have more free time, and teachers' teaching model and interpersonal interactive style will also change. They may feel confused, lost, lonely and depressed, and need help from teachers. Teachers should help them know about the condition of themselves, help them know about their new roles as college students, and help them learn to control their negative emotions.

\section{To Carry Out the Instruction for Learning Method}

Many college freshmen continue to use the learning method in high school. Tutors should help them form new learning method in college, foster their consciousness of independent exploration and form the concept of learning in college. The tutors should provide the instructions on learning for freshmen, help them to remove the bad learning attitude and habit, and help them to learn how to make use of environmental resources effectively.

\section{ACKNOWLEDGEMENTS:}

This article is financially supported by the project "The Integrated Intervention Model for Promoting College Freshmen's Adaptation" (2010B392) of "Eleventh Five-Year Plan" of Hubei Educational Science in 2010.

\section{REFERENCES}

[1] X. Hang, Concise Dictionary of Psychology. Hefei:Anhui People's Publishing House, 2004. pp.348.

[2] F. M. Jonattan, R. H. Gregory and B.L.Brand, Parental Attachment, Separation-Individuation, and College Student Adjustment: A Structural Equation Analysis of Mediational Effects,"in Journal of counseling psychology, vol. II , 2004,pp.213-225.

[3] L.W.Ericka and P. B. Lamia , "An exploratory study of the relationship of family support and coping with adjustment: Implications for college students with a chronic illness,"in Journal of Adolescence, volIII ,2007, pp.365-376

[4] G. R. Kenneth, T.V. Debroah and A. A. Mirela, "Cognitiveaffectivemediators of perfectionism and college student adjustment,"in Personality and Differences,volIII ,2004,pp.463-473.

[5] D. C. Rosalind, "Self-conception patterns of college students, and adjustment to college life,"in Journal of counseling psychology,vol I ,2007, pp.47-52.

[6] Q. Y. Xiang and Y. L. Chen, "College Freshmen's Psychological Conflicts and Countermeasure," in Academic Journal of Sichuan health management Cadre Institute, volIV,2006,pp.294-296.

[7] X. Yang, D. F. Xu and Z. Y. Zhang, "Exploratory analysis of college freshmen's adaptive problems,"in Academic Journal of Liaoning Administration Institute, $\mathrm{Vol} I I$,2010, pp.155-156.

[8] Z. Yuan, "The Study of Common Adaptive Problems of College Freshmen,"in Journal of Chinese Science and Technology Innovation, vol IV, 2009, pp.6-7.

[9] C. X. Liu, Z. G. Ren and Y. Jiang, "The Study of the Relationship Between College Freshmen's Adaptability and Social Support" in Health Medicine Research and Practice in College and University, vol III , 2006,pp.10-13.

[10] D. M. Zhang and X. C. Zhao, "the Experimental Study on Promoting College Freshmen's Environmental Adaptation ," in Psychological Science, volVI,2006, pp.1496-1498.

[11] X. F. Lu, the Construction and Standardization of College Students' Adaptability. Wuhan: Central China Normal University 